\title{
iPhone app an aid in diagnosing concussions
}

$\mathrm{C}$ all it the electronic equivalent of concussion Coles Notes or study guides for coaches and soccer moms.

A new iPhone application, called Concussion Recognition and Response, is offering coaches and parents a means of identifying whether a player has possibly suffered a concussion.

Developers stress that the app is by no means a replacement for an examination by a trained professional but they're hopeful that it could be an effective tool for recognizing a "suspected concussion," particularly in the absence of trained medical professionals, who are often not in attendance at amateur sporting events.

Playing with an unrecognized concussion can prolong or worsen symptoms, or in exceptional cases, be lifethreatening, says Dr. Laura Purcell, president, Paediatric Sport and Exercise Medicine Section, for the Canadian Paediatric Society. Players under 20 also run the risk of developing a rare condition called second impact syndrome, whereby fatal brain swelling can occur if a player sustains a second injury while they are symptomatic. "The concern we have with that condition is it's seen only in younger age groups."

Although a new app, the wording for certain components of Concussion Recognition and Response came from a Center for Disease Control and Prevention (CDC) initiative that has already recorded success in concussion recognition and awareness.

The Heads Up: Concussion in Youth Sports initiative created paper-based tool kits for parents and coaches, filled with fact sheets, magnets and posters. A study of that initiative found that $77 \%$ of coaches reported being able to more readily identify a possible concussion, while $63 \%$ reported viewing concussions more seriously (www.cdc.gov /concussion/pdf/Heads_Up_Activity _Report_Final-a.pdf).

No such figures yet exist for the app, but the technological tool looks for two key components for a suspected con-

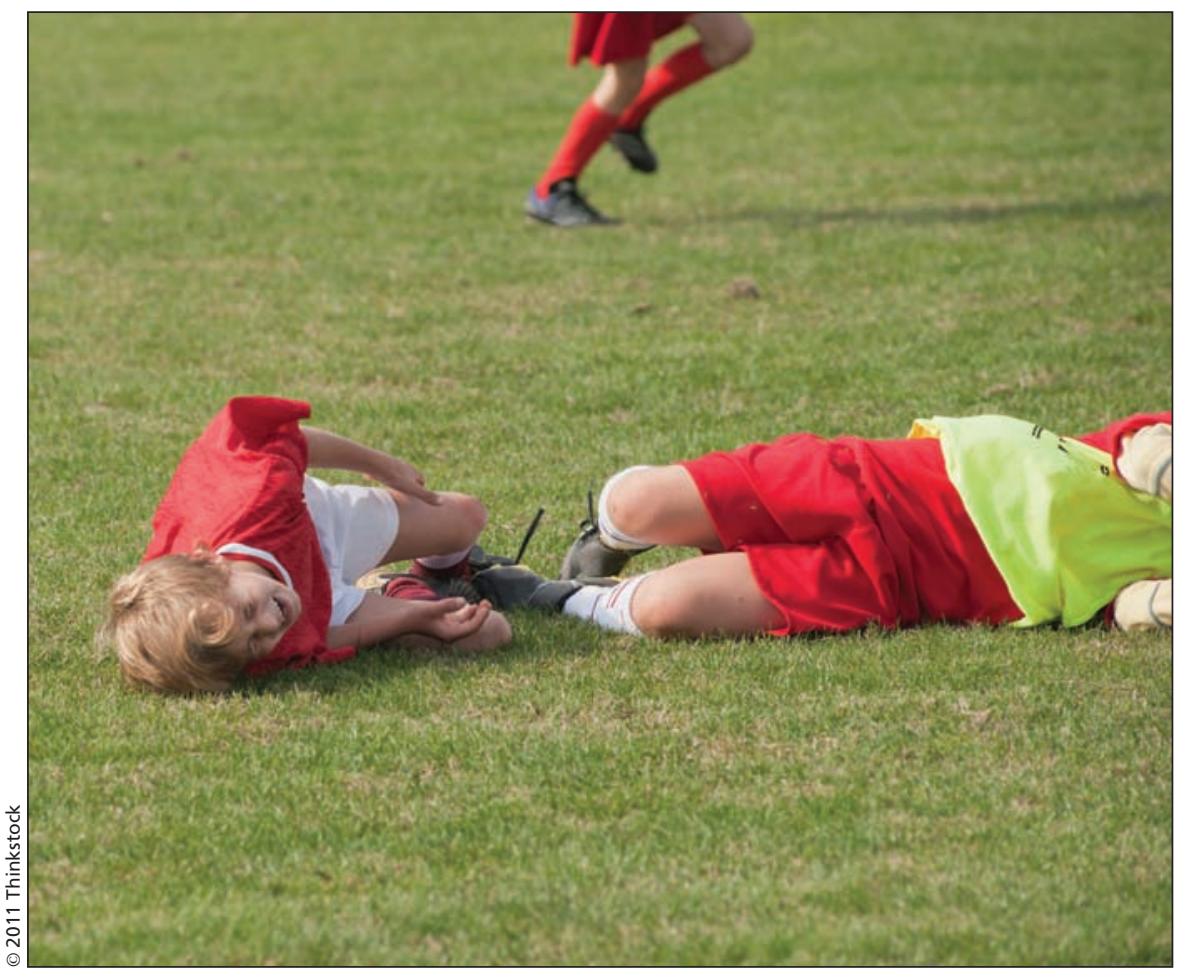

A new iPhone application is offering sports coaches and parents a means of identifying whether injured players have possibly suffered concussions.

cussion: a blow to the head, and a subsequent sign or symptom, such as a headache, drowsiness, amnesia or loss of consciousness.

The first question in the app asks: "was there likely a blow to the head or body, jerking the head?" If the person answers "yes" or "not sure" and clicks "yes" to any one sign or symptom, the app will automatically identify a "suspected concussion" and suggest the person seek medical evaluation. If you click "no" to the first question, you still have the option to go through signs and symptoms.

"In some respects we are probably erring on the side of caution and we'll have what they call some false positives, meaning there will be some kids identified who will turn out not to have a concussion, but we want to err on that side," says Gerald Gioia, who codeveloped the app after spending eight years developing material for the CDC initiative and is the director of the concussion program at the Children's National Medical Center in Washington, DC.

The app rightly acknowledges that you don't need to have a head injury to sustain a concussion, says Dr. James Kissick, sports medicine physician at the Ottawa Sport Medicine Centre in Ontario. But he notes that no matter how many symptoms you enter, if you clicked "no" to a likely blow to the head or body, the app will not indicate a suspected concussion.

In such a case, the app does respond with "although you do not indicate both elements of a suspected concussion, if you are still not sure about an injury, you should follow the rule 'when in doubt, sit them out'," he says, adding that while that is good advice, the failure to advise people to seek medical attention is a concern.

In addition to helping coaches and parents recognize concussions, the app also includes a concussion management section with treatment strategies and 
answers to commonly asked questions, such as whether a child should be riding a bike, when they can play sports again or when they should return to school.

The app will also serve as a research tool. Proceeds from purchase of the app (for US\$3.99 from iTunes) will be used toward concussion research. Purchasers are asked for permission to collect their injury information, such as the signs and symptoms of the injury, the sport and the geographic location of the incident, in a central database. The data collected will allow researchers to examine "the reality of this injury literally in real time."

Giola says the CDC is currently considering a formal research partnership with the app's publisher, Psychological Assessment Resources. Gail Hayes, spokeswoman for the CDC Injury Center, confirms in an email that such a partnership is under consideration.
Giola adds that several other concussion-related apps are now under development. One is aimed at helping physicians assess head injuries in a more systematic fashion, while the other is a "first-responder" app for trainers at athletic events or paramedics responding to car accidents. - Erin Walkinshaw, Ottawa, Ont.

CMAJ 2011. DOI:10.1503/cmaj.109-3942 